\title{
Profile and Areal Surface Parameters for Fatigue Fracture Characterisation
}

\author{
Wojciech Macek ${ }^{1,}{ }^{*}$, Ricardo Branco ${ }^{2}$, Mirosław Szala ${ }^{3}$, Zbigniew Marciniak ${ }^{4}$, Robert Ulewicz ${ }^{5}$, \\ Norbert Sczygiol ${ }^{6}$, Piotr Kardasz ${ }^{7}$ \\ 1 Opole University of Technology, 76 Proszkowska St., 45-758 Opole, Poland; email: \\ wojciech.macek@yahoo.com (W.M.); \\ 2 University of Coimbra, CEMMPRE, Department of Mechanical Engineering, Rua Luís Santos, 3030-788 \\ Coimbra, Portugal; email: ricardo.branco@dem.uc.pt (R.B.); \\ 3 Department of Materials Engineering, Faculty of Mechanical Engineering, Lublin University of \\ Technology, Nadbystrzycka 36D, 20-618 Lublin, Poland; m.szala@pollub.pl (M.S.); \\ 4 Opole University of Technology, ul. Mikolajczyka 5, 45-271 Opole, Poland; email: z.marciniak@po.edu.pl \\ (Z.M.); \\ 5 Czestochowa University of Technology, Czestochowa, Poland; email: robert.ulewicz@wz.pcz.pl (R.U.); \\ 6 Czestochowa University of Technology, Czestochowa, Poland; email: norbert.strzygiol@pcz.pl (N.S.); \\ 7 Wroclaw School of Information Technology, 54-239 Wrocław, Lutra 4, Poland; email: \\ pkardasz@horyzont.eu (P.K.); \\ * Correspondence: wojciech.macek@yahoo.com;
}

\begin{abstract}
Post-mortem characterisation is a pivotal tool to trace back to the origin of structural failures in modern engineering analyses. This work presents a comparison of both the crack propagation profiles and the rupture roughness profiles based on areal parameters for total fracture area. Notched and smooth samples made of weather-resistant structural steel (10HNAP), popular S355J2 structural steel and aluminium alloy AA2017A under bending, torsion, and combined bending-torsion are investigated. After the fatigue tests, fatigue fractures are measured with an optical profilometer, and the relevant surface parameters are critically compared. The results show a great impact of the loading scenario on both the local profiles and the total fracture areas. In this work, the results of both approaches (local and total fracture zones) for specimens with different geometries are investigated. For all specimens, measured texture parameters decreased in the following order: total area, rupture area, and propagation area.
\end{abstract}

Keywords: Surface metrology; surface topography; bending-torsion fatigue; fatigue fracture.

\section{Introduction}

Post-mortem analysis is a fundamental engineering procedure to identify the damage accumulation mechanisms associated with the fatigue failure. This analysis may provide important clues to improve the materials performance, or to evaluate both structural and mechanical properties, as well as to mitigate the damage mechanisms [1-3].

Much research connected with surface metrology has been focused on extensive investigations in which 3D surface roughness parameters have been presented in light of the relationship between surface properties and operation properties [4-8]. Although this analysis provides useful information, post-failure fractographic surface examinations allow the cause of failure in materials to be determined [9-12]. Researchers have studied the characteristics of fractured surfaces using observational tools, from macro to nanoscale [13-17]. Unfortunately, even though the advanced methods such as optical coherence tomography [18], scanning acoustic microscopy [19] or energy response approach which base on strain energy density histories during variable loading [20,21] are described in the literature, usually simple-fracture qualitative analysis investigation, conducted with usage of scanning electron microscopy, are employed for evaluation a surface fractures resulting due 
to impact [22,23], tensile strength [24,25], fatigue [5,19], ultra-high fatigue [26], adhesion testing [27] or even wear damage description [28,29]. However, limited papers study the profile and surface roughness usage as a tool for fatigue fracture characterization.

Moreover, there are few papers devoted to the quantitative analysis of fracture surfaces in elements undergoing combined bending-torsion loading histories [30-33]. Therefore, the present paper aims to study the bending-torsion fatigue fractures in order to establish the dependence between the loading scenario and the characteristic features of their surfaces. Work in the open literature describes the influence of loading conditions on topography of fracture surfaces via either local terms, i.e. crack propagation and rupture [34-38], or based on the analysis of the total area of fracture $[39,40]$. In this work, the results of both approaches (local and total fracture zones) for specimens with different geometries are compared for three materials. For different loading scenarios (which encompass bending, torsion, and bending-torsion) 2D and 3D surface texture measurement methods are adopted, and the main results are critically compared.

\section{Materials and Methods of Measurement}

\subsection{Materials and specimens}

The material grades studied in the present research were: (a) the 10HNAP weather-resistant structural steel [39]; (b) the S355J2 structural steel [41]; and (c) the 2017A-T4 aluminium alloy [42]. The components manufactured from tested metal alloys are popular in machine building industry, therefore, can undergo the fatigue. The nominal chemical composition and mechanical properties are summarized, respectively, in Tables 1 and 2.

Table 1. Chemical composition of the tested alloys (wt.\%).

\begin{tabular}{cccc}
\hline Element & 10HNAP & S355J2 & AA2017A-T4 \\
\hline $\mathrm{C}$ & 0.115 & 0.21 & - \\
$\mathrm{Si}$ & 0.41 & 0.42 & 0.45 \\
$\mathrm{Mn}$ & 0.71 & 1.46 & 0.65 \\
$\mathrm{P}$ & 0.082 & 0.019 & - \\
$\mathrm{S}$ & 0.028 & 0.046 & - \\
$\mathrm{Cr}$ & 0.81 & 0.09 & 0.10 \\
$\mathrm{Ni}$ & 0.50 & 0.04 & - \\
$\mathrm{Cu}$ & 0.30 & 0.17 & 4.15 \\
$\mathrm{Zn}$ & - & - & 0.50 \\
$\mathrm{Mg}$ & - & - & 0.69 \\
$\mathrm{Ti}$ & - & - & 0.20 \\
$\mathrm{Al}$ & - & - & Balance \\
$\mathrm{Fe}$ & Balance & Balance & 0.70 \\
\hline
\end{tabular}

Table 2. Main mechanical properties of the tested alloys.

\begin{tabular}{lccc}
\hline \multicolumn{1}{c}{ Material properties } & 10HNAP & S355J2 & AA2017A-T4 \\
\hline Ultimate tensile stress, $\sigma_{\mathrm{u}}(\mathrm{MPa})$ & 566 & 535 & 480 \\
Yield stress $\sigma_{\mathrm{y}}, \mathrm{MPa}$ & 418 & 357 & 382 \\
Elongation A10 (\%) & 30.1 & 21 & 23 \\
Reduction of area RA (\%) & 36.5 & 50 & 50 \\
Young's modulus E (GPa) & 215 & 210 & 72 \\
Poisson's ratio $v$ & 0.29 & 0.30 & 0.32 \\
\hline
\end{tabular}


Specimens used in the experimental fatigue campaign are depicted in Figure 1, and comprised: (a) cylindrical 10HNAP steel specimens with a circumferential V-notch (see Fig. 1a); specimens with a circular cross-section (see Fig. 1b); and 2017A-T4 aluminium rectangular cross-section specimens with a V-notch (Fig. 1c). Both V-shaped configurations had external, unilateral, sharp and blunt onesided notches, with radius $\mathrm{r}=0.2 \mathrm{~mm}, 5 \mathrm{~mm}, 10 \mathrm{~mm}$ and $22.5 \mathrm{~mm}$ and notch-angles of $60^{\circ}$.
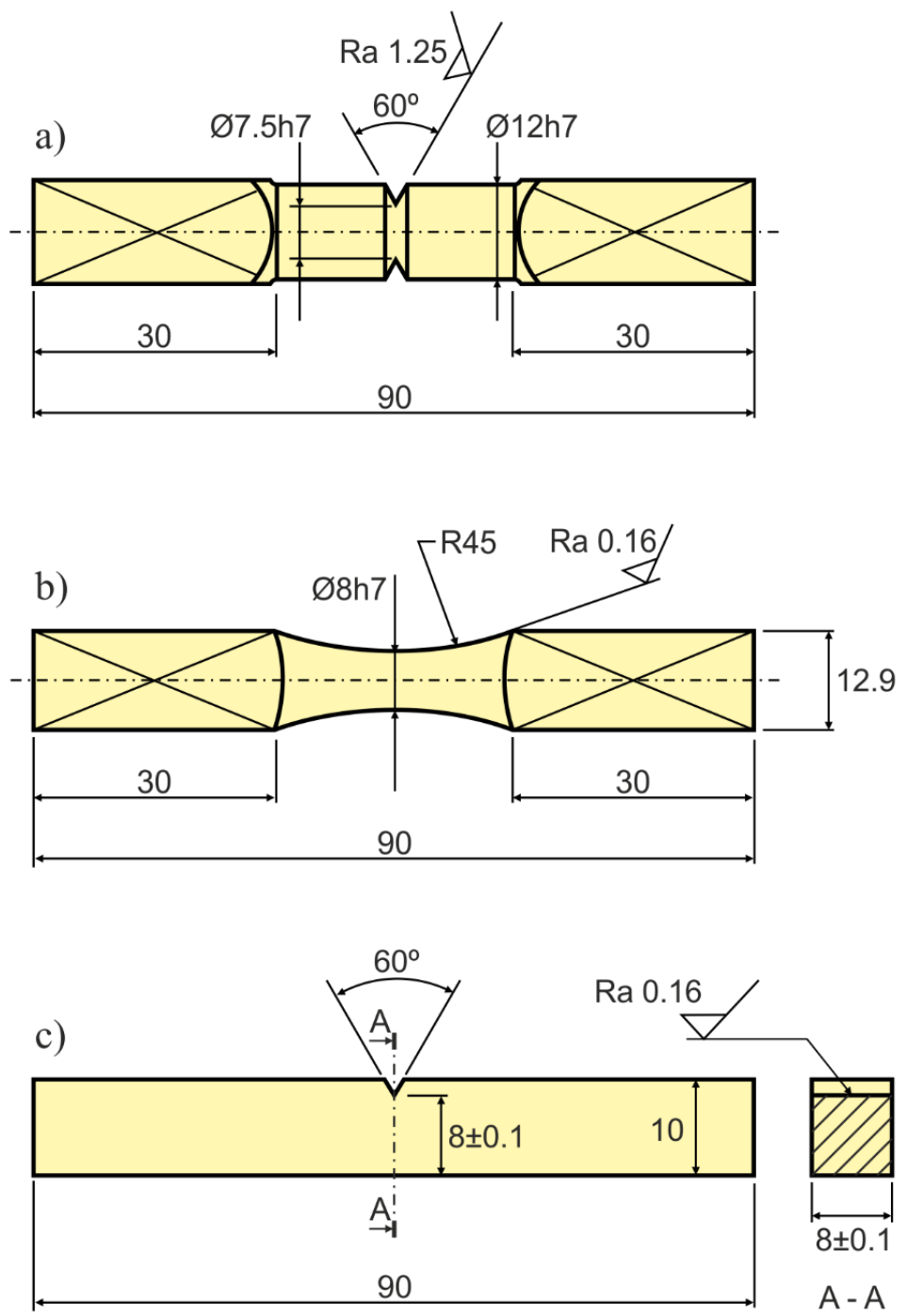

Figure 1. Specimen geometries: (a) V-notched circular cross-section specimen made of 10HNAP steel; (b) smooth circular cross-section specimen made of S355J2 steel; and (c) V-notched rectangular crosssection specimen made of 2017A-T4 aluminium alloy (dimensions in millimeters).

\subsection{Loading histories}

All specimen geometries were tested under combined bending-torsion, bending and torsion (except geometry b). For the 10HNAP steel samples, stationary and ergodic random loadings had a normal probability distribution and wide-band frequency spectra from 0 to $60 \mathrm{~Hz}$. In the case of mixed loading, nominal normal stress amplitudes were equal to nominal shear stress amplitudes, i.e. $\sigma_{a}=\tau_{a}$. Fatigue tests of S355J2 steel specimens encompassed non-proportional bending-torsion histories with different ratios of the maximum shear stress to the maximum normal stress, i.e. $\lambda=\tau_{\max } / \sigma_{\max }$. In the case of the 2017A-T4 aluminum alloy specimens, tests have conducted under different bending-to-torsion amplitudes ratios. The stress ratios $(R)$ used in this experimental campaign were $R=-1,-0.5,0$ [32]. 


\subsection{Surface parameter measurement and calculation}

Fracture surface analysis was performed using an optical 3D test stand facilitating the acquisition of data sets at a high depth of focus [43,44]. The failed specimens were observed under 10x magnification using an Alicona G4 InfiniteFocus accordingly to the procedure described in the previous work [45]. The above-mentioned measurement device, exhibited in Figure 2, is operated via the IFMeasureSuite software, while the measurement of surfaces features was conducted through the MountainsMap software. Fatigue fracture surfaces were measured for local (propagation and rupture) profiles and for total areas Figure 3 shows examples of the propagation areas and main surface parameters as well as rupture areas and main texture parameters observed in the experiments for the three metal alloys studied here.

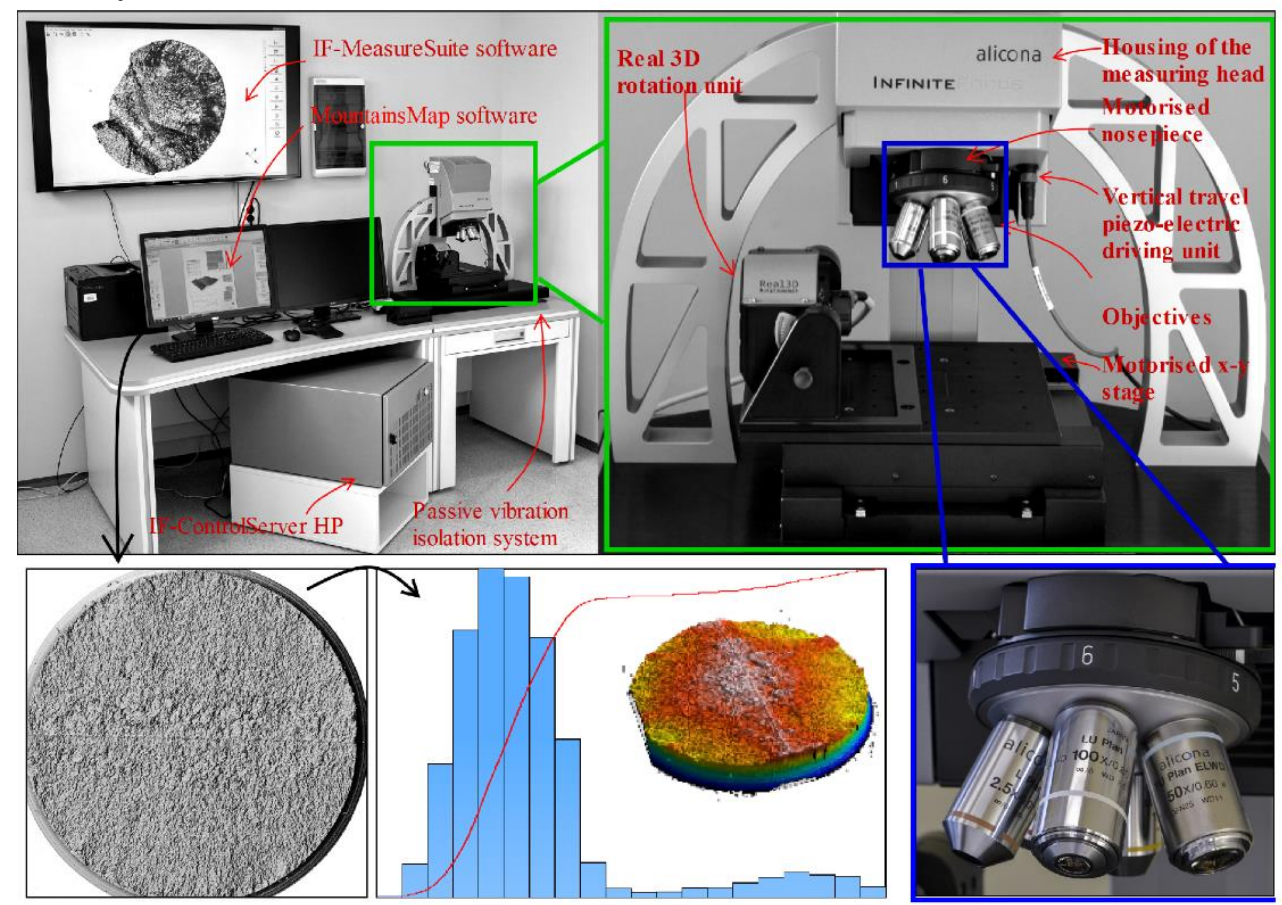

Figure 2. InfiniteFocus IF G4 measurement device used in surface metrology.

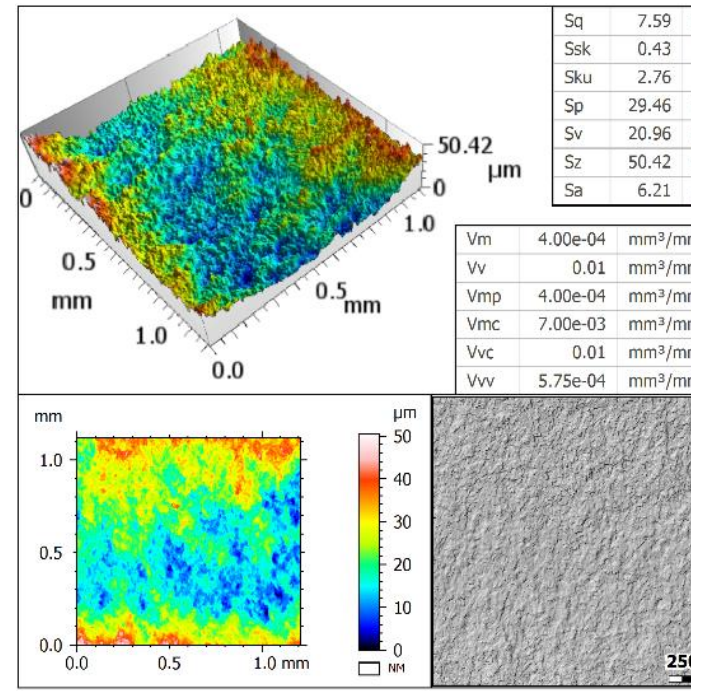

a)

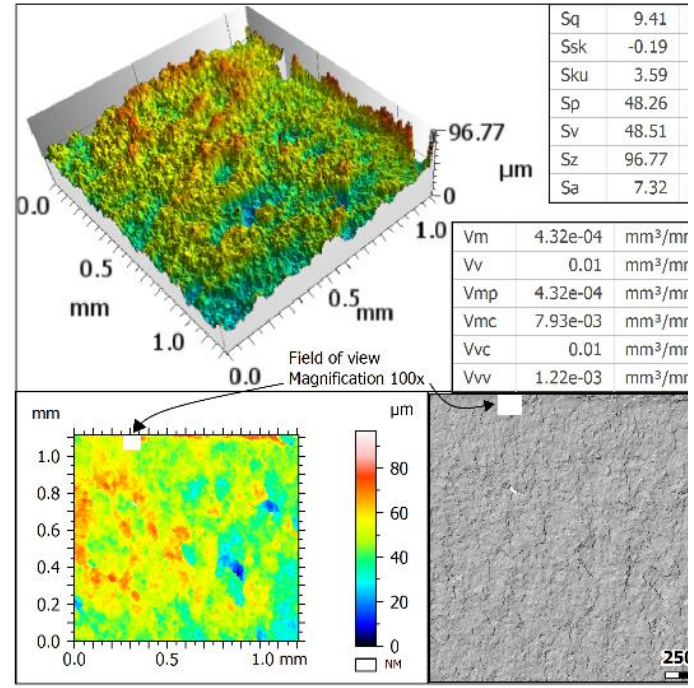

d) 


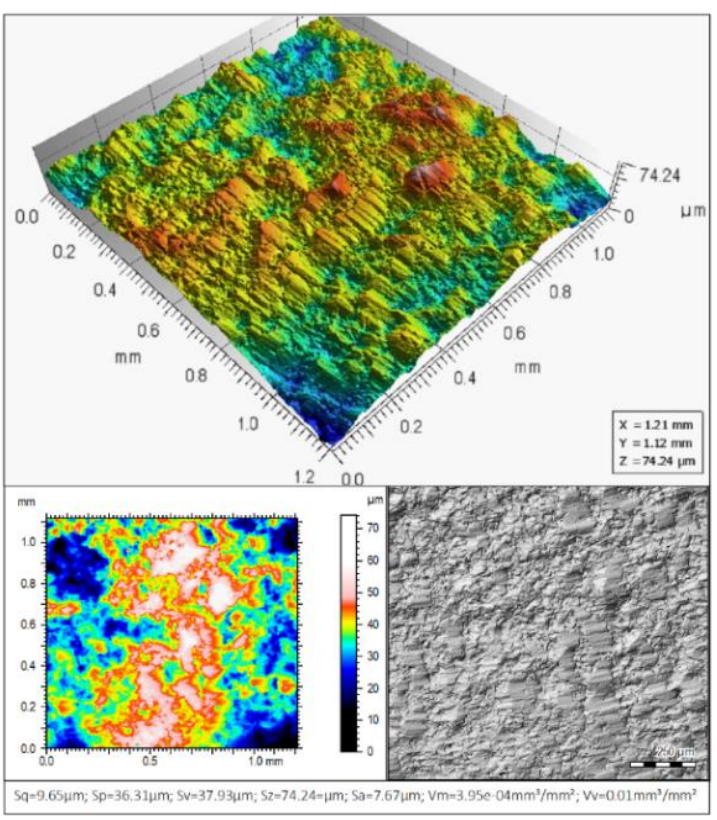

b)

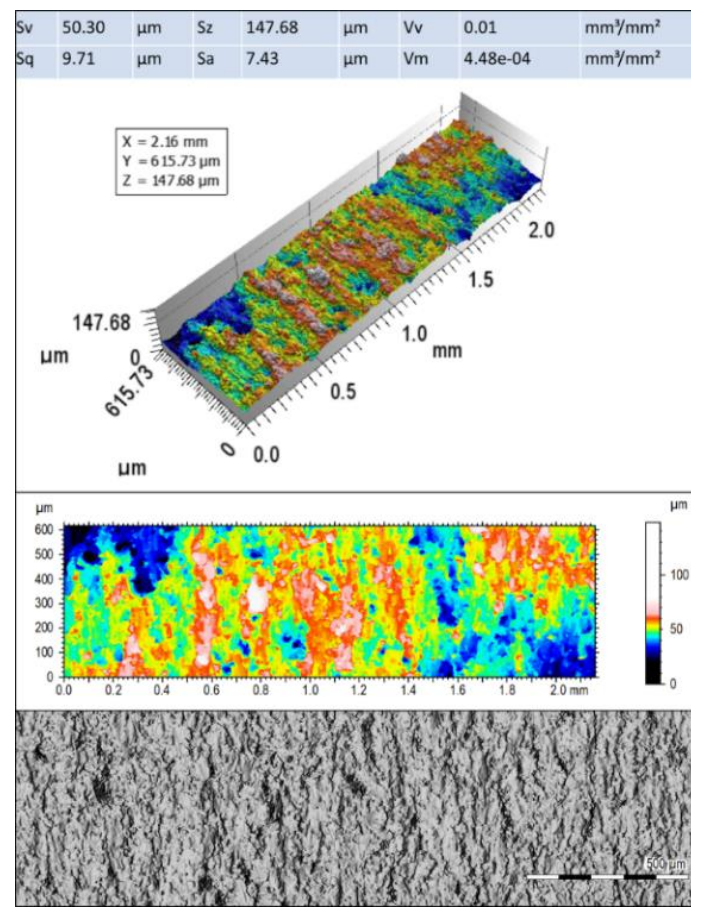

c)

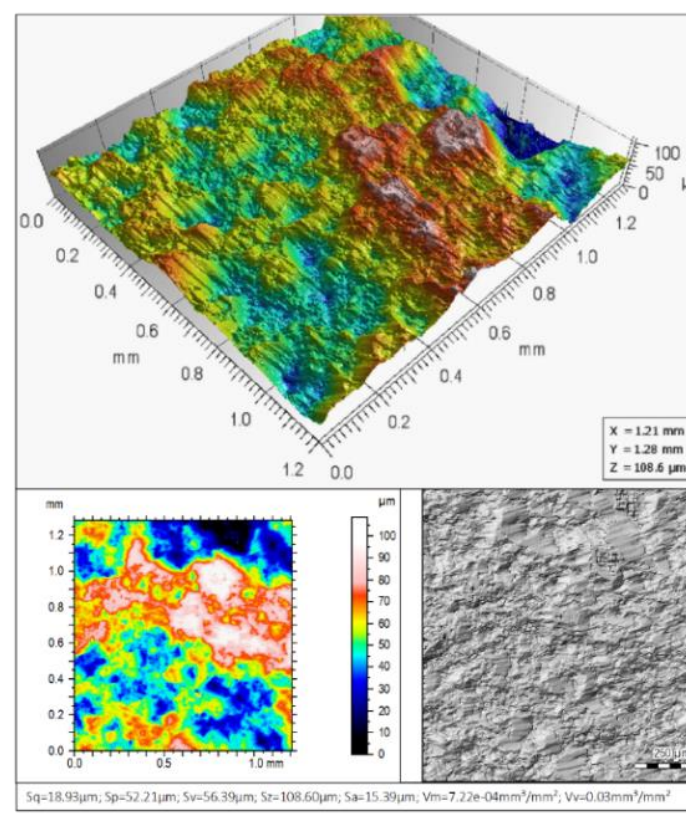

e)

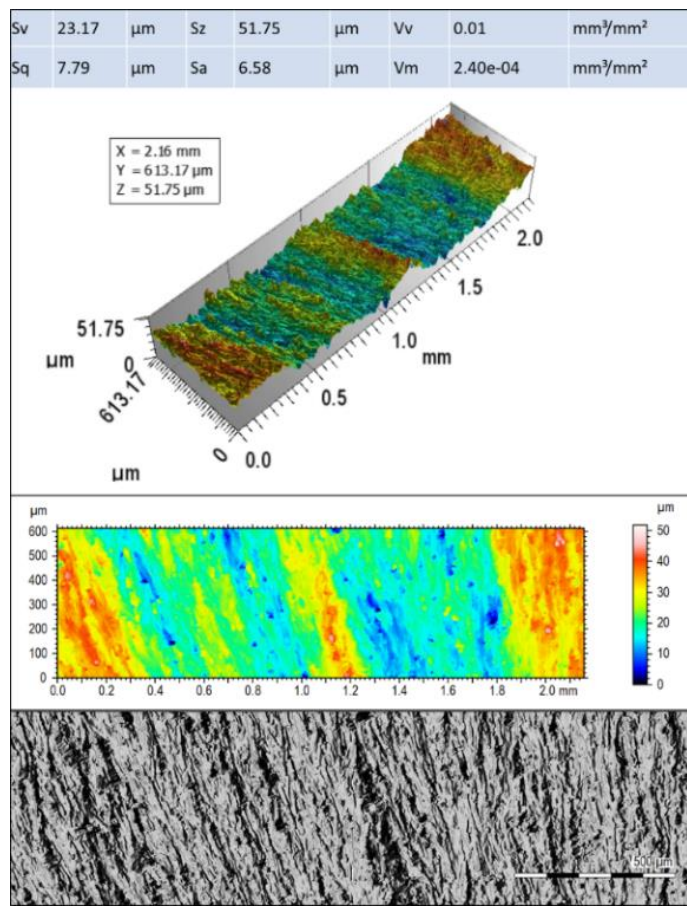

f)

Figure 3. Propagation area view of the specimen made of: (a) 10HNAP steel; (b) S355J2 steel; and (c) 2017A-T4 aluminium alloy. Rupture area view of the specimen made of: (d) 10HNAP steel; (e) S355J2 steel; and (f) 2017A-T4 aluminium alloy.

It is known that the microrelief of fatigue fracture surface is determined by the material properties and the stress intensity factor in the tip of initial crack; therefore, the parameters of the microrelief depend on the stress amplitude and the fatigue crack length. When testing ductile materials, the height of the fracture profile usually increases with increasing crack length, and the stage of the fatigue crack propagation, three zones with different roughness are found: the initial zone with a predominant shear microrelief, the zone with striation microrelief and the zone of accelerated crack growth, in which striations and dimples are observed. With an increase in the stress amplitude, the size of the zones changes, the zone with striations decreases, and the zone of rupture grows. When testing brittle or quasi-brittle materials, the height of the fracture profile often decreases with increasing crack length as 
a result of formation of facets of cleavage or intergranular fracture [46,47]. Overall, there are obvious differences in topography either for propagation or rupture, particularly the coarser areas. Ra (Eq. (1)) averages all peaks and valleys of the roughness profile and then neutralizes the few outlying points, so that the extreme points have no significant impact on the final results. As far as the Sa is concerned, as expressed in Eq. (2), it represents the mean height of the surface, according to the ISO 25178 standard. Their functionality is analyzed later in the work.

$$
\begin{gathered}
R a=\frac{1}{l r} \int_{0}^{l r}|z(x)| d x \\
S a=\frac{1}{A} \iint_{A}|z(x, y)| d x d y
\end{gathered}
$$

\section{Results and discussion}

Figure 4 shows representative surface texture measurement results for both local profiles (in terms of propagation and rupture) and for total areas. In fact, as anticipated in the previous figure, the comparison of the different evaluated parameters for the three materials shows important differences.

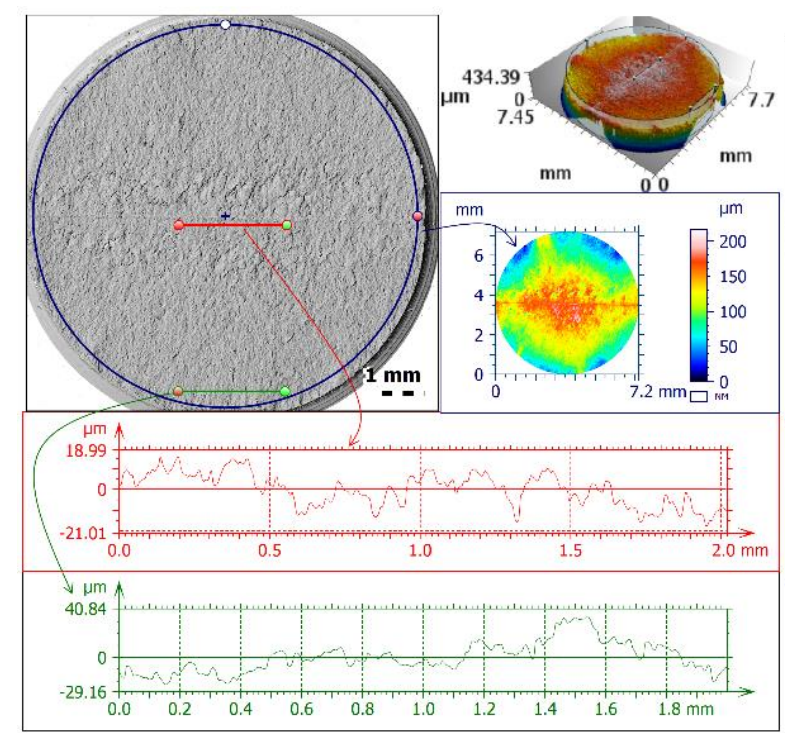

a)

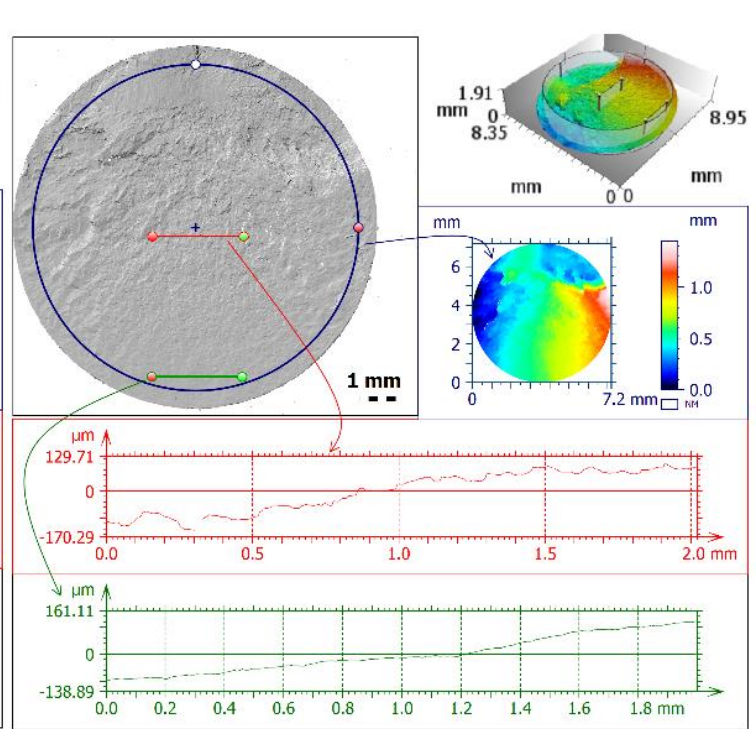

b)

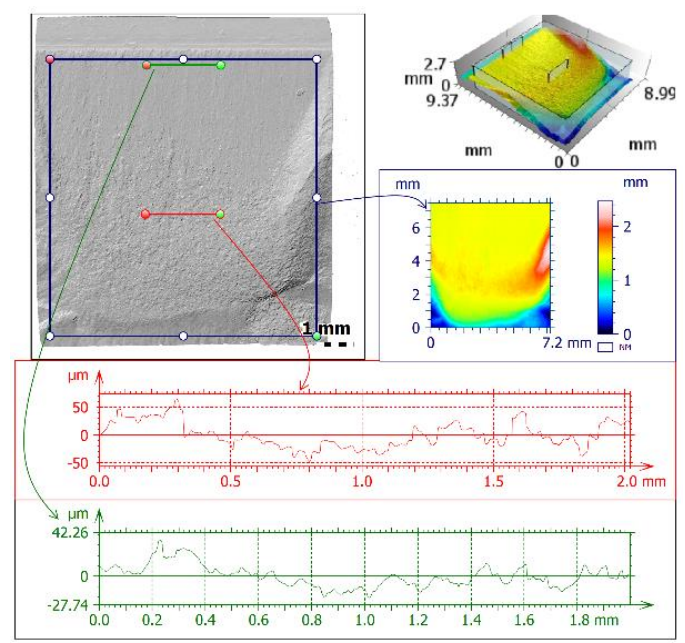

c)

Figure 4. Fractures with marked crack propagation profile, rupture roughness profile, and extracted total area for exemplary specimens made of: (a) 10HNAP steel; (b) S355J2 steel; and (c) 2017A-T4 aluminium alloy. 
Some specific features of the tested specimens initially noticed in the measurement results were analysed at this point. For further analysis, Ra and Sa were selected from R- and S- parameters. These parameters demonstrated the best fit, evident dependence on the loading condition, and widespread use, regardless of the measuring technique.

Figure 5 presents an extract of all analysed results Ra and Sa, by type of loading. Without qualifying the method and place of measuring the fractured surface, it can be seen that generally, the highest values occur for a mixed-mode loading and the lowest for torsion.

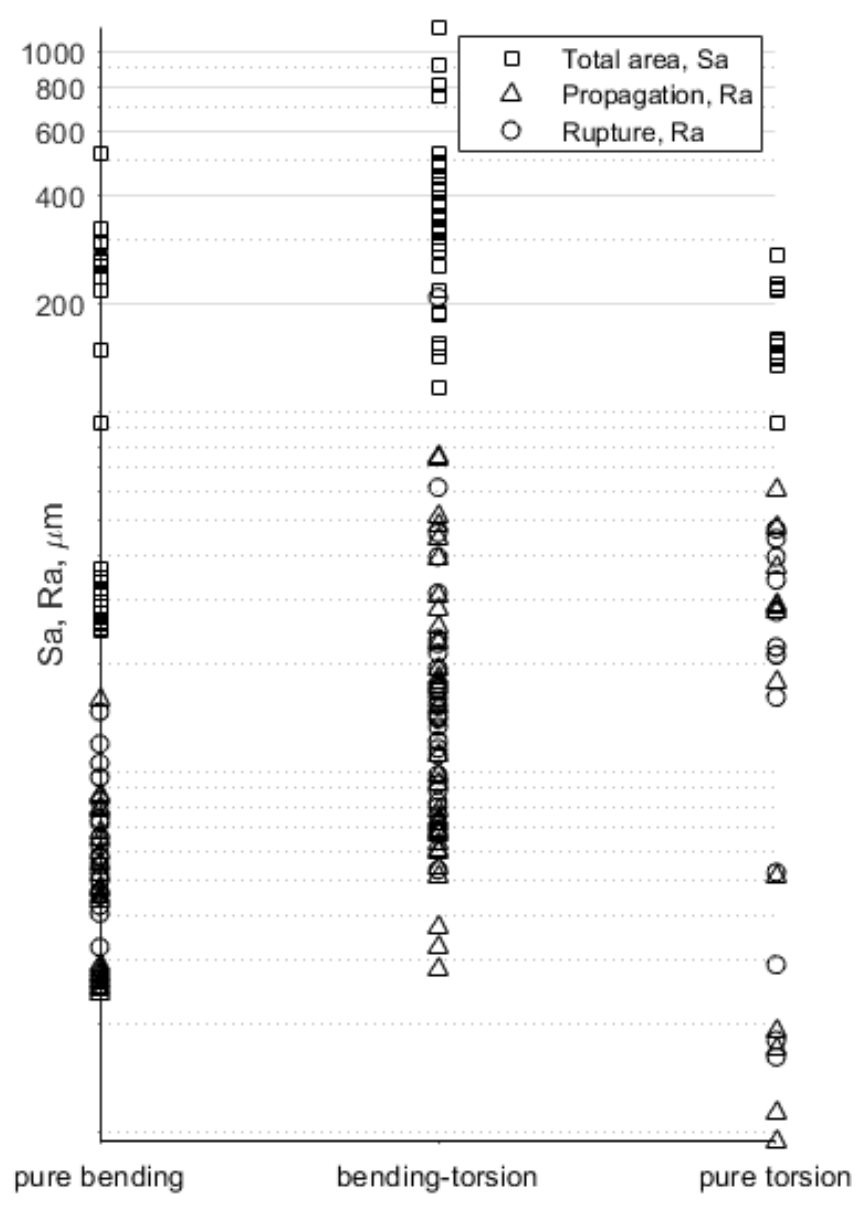

Figure 5. Results Ra and Sa by type of loading.

Figures 6a-c present the results of all specimens divided into three analysed ways of identifying the fracture, i.e. total area, propagation profile, and rupture profile, respectively. For the results of measurements of the total fracture surface Sa parameter (likewise Ra for propagation profile), the highest values as well as the greatest dispersion were obtained for bending-torsion. The 10HNAP specimens are the exception. For this case, the torsion Ra parameter had the highest values (see Table 3 ). In the case of torsion, for which only measurements of samples (a) and (c) were taken, the latter take the lowest values. 


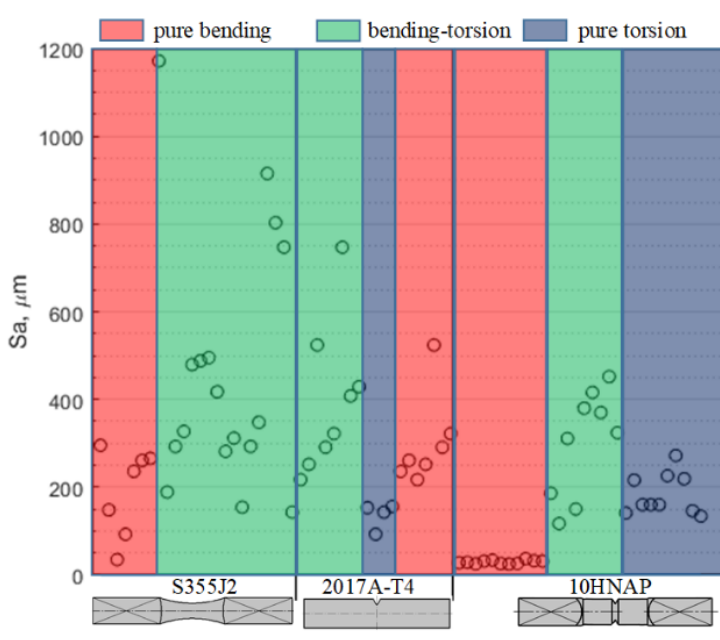

a)

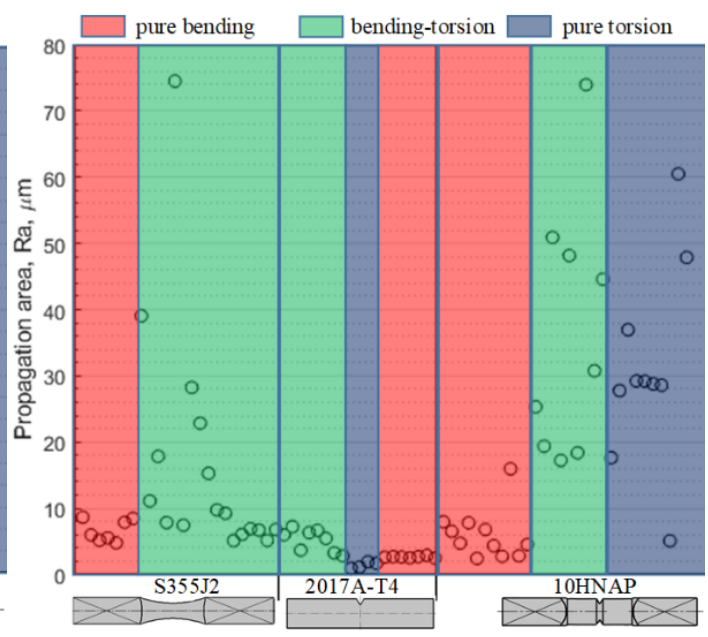

b)

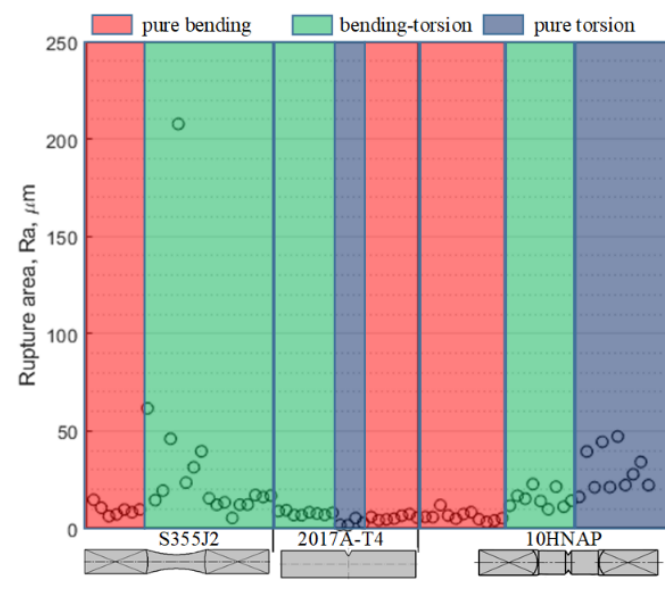

c)

Figure 6. Surface parameters for the investigated fracture areas: (a) total area; (b) propagation profile; and (c) rupture profile.

Table 3. List of maximum and minimum values of surface parameters for individual reference area.

Specimen

\section{Method}

\begin{tabular}{lccc}
\cline { 2 - 4 } & 10HNAP & S355J2 & 2017A \\
\hline Total area max. & BT & BT & BT \\
Propagation profile max. & BT & BT & BT \\
Rupture profile max. & T & BT & BT \\
Total area min. & B & B & T \\
Propagation profile min. & B & B & T \\
Rupture profile min. & B & B & T \\
\hline
\end{tabular}

BT: Bending-torsion; T: torsion; B: bending 
Table 4. Median extremum for individual reference areas.

\begin{tabular}{lccc}
\hline \multicolumn{1}{c}{ Reference area /median extremum } & bending & bending-torsion & torsion \\
\hline Total area & MIN. & MAX. & \\
Propagation profile & MIN. & & MAX. \\
Rupture profile & MIN. & & MAX. \\
\hline
\end{tabular}

In statistical terms, the dependence of surface parameters on the type of loading was presented using box plots with, among other things, percentiles. On each box (see Fig. 7), the central mark indicates the median, and the bottom and top edges of the box indicate the 25th and 75th percentiles, respectively. The whiskers extend to the most extreme data points not considered outliers, and the outliers are plotted individually using the '+' symbol.

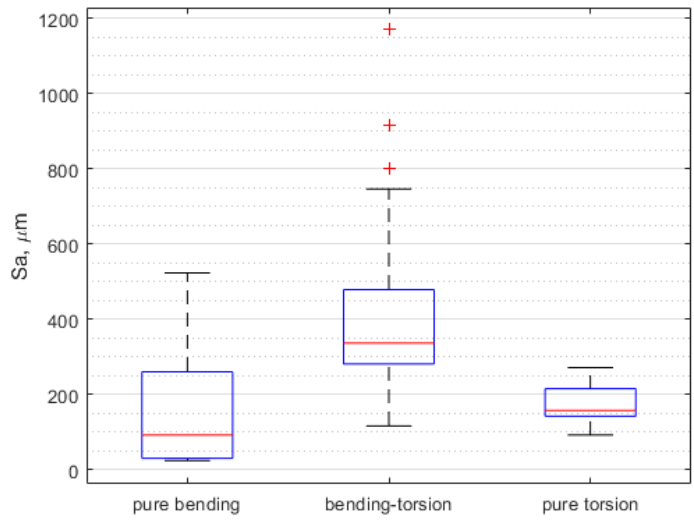

a)

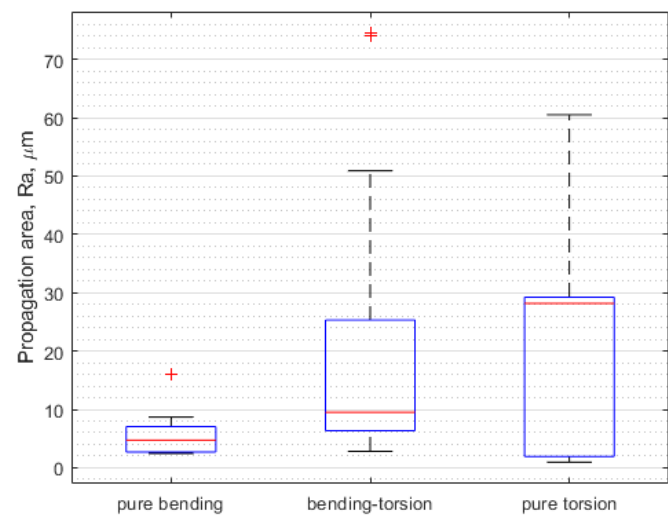

b)

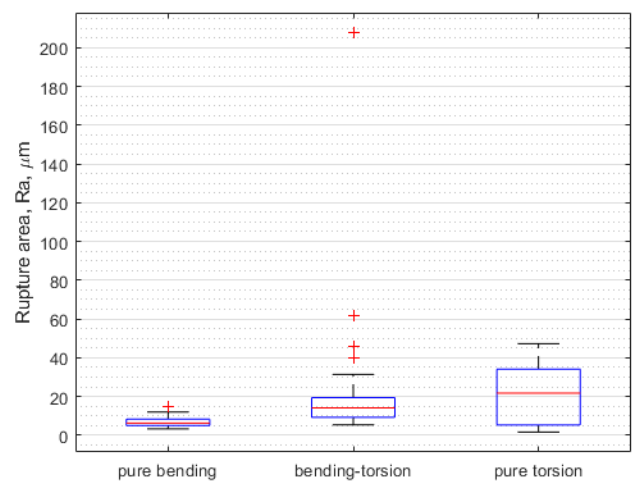

c)

Figure 7. Box plots for results: (a) total fracture area; (b) propagation profile; (c) rupture profile.

As we can see in Figure 7a, the median Sa for all bending specimens is approximately $100 \mu \mathrm{m}$. The minimum value is about $10 \mu \mathrm{m}$, and the maximum value is about $550 \mu \mathrm{m}$. For bending-torsion and torsion, respectively, these values are median Sa $340 \mu \mathrm{m}$ and $150 \mu \mathrm{m}$, minimum value $110 \mu \mathrm{m}$ and $100 \mu \mathrm{m}$, and maximum value $750 \mu \mathrm{m}$ and $270 \mu \mathrm{m}$. Next, taking into account only the medians for propagation area (Figure 6b), Ra expressed in micrometres equals about 5 for bending, 10 for bending-torsion, and 28 for torsion loadings. For rupture area, the measurements are $7 \mu \mathrm{m}, 14 \mu \mathrm{m}$ and $21 \mu \mathrm{m}$. Table 4 summarises the medians extremum of measurement results for all specimens broken down into reference area and loading scenario. Clear and evident relationships between the size of surface parameters for individual analysed fracture zones are shown in Figures 2-6. In summary, these relationships can be expressed as: total area > rupture area > propagation area.

\section{Conclusions}


This study presents methods for metrological characterisation and comparison of fatigued fractures using post-failure measurements. Combining various techniques and fields of science ensure a more complete analysis of the issue. Investigation of the entire fracture surface taking into account various factors gives greater opportunities to find the causes of failures. The proposed methodologies were tested under different loading histories, namely bending, torsion, and combined bending-torsion; and different materials (structural steels and aluminium alloy); and specimen geometries (smooth and notched samples). Defects can be associated with the formation of propagation area, rupture area and total fracture area due to fundamentally different mechanisms and driving force for the process zone evolution and the crack advance. However based on the undertaken analysis and comparisons, the following general conclusions can be drawn:

- Entire total area method is more universal and burdened with less error than the subjective method of measurement in individual fracture zones for various shape-types of fatiguetested samples;

- This method is suitable for assessment and supplements the testing of materials damaged as a result of fatigue loads, for various shapes of the tested detail;

- Both profile and areal surface parameters are essential for fatigue fracture mechanism characterization. However, if we compare profiles R- roughness and areal S- roughness parameters, the latter give complete information, because a single line cannot identify pits or valleys, and shows the relationship between surface function. 3D measurements give far more comprehensive information than 2D profiles or sections;

- For both zones (propagation and rupture), median of Ra grows along with the increase in the proportion of torsional loadings. Otherwise, for total area, the mixed mode caused the highest average Sa value, and this conclusion can be considered appropriate given the greater accuracy of this method. This is also confirmed by the results for the individual types of specimens;

- For all specimens, measured texture parameters decreased in the following order: total area, rupture area, and propagation area.

Further research should focus on the suitability of entire total area method for a wider range of metallic and composite materials, and types of loadings.

Author Contributions: writing - original draft preparation, W.M., R.B.; Investigation, W.M., Z.M.; writingreview and editing, W.M., R.B., M.S., Z.M., R.U., N.S., P.K.; All authors have read and agreed to the published version of the manuscript.

Conflicts of Interest: The authors declare no conflict of interest.

\section{Acknowledgements}

The project/research was financed in the framework of the project Lublin University of Technology Regional Excellence Initiative, funded by the Polish Ministry of Science and Higher Education (contract no. 030/RID/2018/19).

\section{References}

1. Ulewicz, R.; Nový, F.; Novák, P.; Palček, P. The investigation of the fatigue failure of passenger carriage draw-hook. Engineering Failure Analysis 2019, 104, 609-616, doi:10.1016/j.engfailanal.2019.06.036.

2. Branco, R.; Antunes, F.V.; Costa, J.D.; Yang, F.P.; Kuang, Z.B. Determination of the Paris law constants in round bars from beach marks on fracture surfaces. Engineering Fracture Mechanics 2012, 96, 96-106, doi:10.1016/j.engfracmech.2012.07.009.

3. Su, Y.; Yu, F.-H.; Han, Q.-N.; Shang, Y.-B.; Rui, S.-S.; Li, J.; Shi, H.-J.; Niu, L.-S. Failure analysis of runway centerline light and effect of microstructure on mechanical properties. Engineering Failure Analysis 2019, 105, 1069-1078, doi:10.1016/j.engfailanal.2019.07.051. 
4. Branco, R.; Costa, J.D.; Berto, F.; Antunes, F.V. Effect of loading orientation on fatigue behaviour in severely notched round bars under non-zero mean stress bending-torsion. Theoretical and Applied Fracture Mechanics 2017, 92, 185-197, doi:10.1016/j.tafmec.2017.07.015.

5. Lesiuk, G.; Rymsza, B.; Rabiega, J.; Correia, J.A.F.O.; De Jesus, A.M.P.; Calcada, R. Influence of loading direction on the static and fatigue fracture properties of the long term operated metallic materials. Engineering Failure Analysis 2019, 96, 409-425, doi:10.1016/j.engfailanal.2018.11.007.

6. Azevedo, C.R.F.; Marques, E.R. Three-dimensional analysis of fracture, corrosion and wear surfaces. Engineering Failure Analysis 2010, 17, 286-300, doi:10.1016/j.engfailanal.2009.06.010.

7. Szala, M.; Walczak, M.; Pasierbiewicz, K.; Kamiński, M. Cavitation Erosion and Sliding Wear Mechanisms of AlTiN and TiAlN Films Deposited on Stainless Steel Substrate. Coatings 2019, 9, 340, doi:10.3390/coatings9050340.

8. Macek, W.; Owsiński, R.; Trembacz, J.; Branco, R. Three-dimensional fractographic analysis of total fracture areas in 6082 aluminium alloy specimens under fatigue bending with controlled damage degree. Mechanics of Materials 2020, 147, 103410, doi:10.1016/j.mechmat.2020.103410.

9. Fracture Appearance and Mechanisms of Deformation and Fracture. In Failure Analysis and Prevention; Becker, W.T., Shipley, R.J., Eds.; ASM International, 2002; pp. 559-586 ISBN 978-1-62708-180-1.

10. Lynch, S.P.; Moutsos, S. A brief history of fractography. J Fail. Anal. and Preven. 2006, 6, 54-69, doi:10.1361/154770206X156231.

11. Miletić, I.; Ilić, A.; Nikolić, R.R.; Ulewicz, R.; Ivanović, L.; Sczygiol, N. Analysis of Selected Properties of Welded Joints of the HSLA Steels. Materials (Basel) 2020, 13, doi:10.3390/ma13061301.

12. Taira, S.; Tanaka, K.; Ryu, J.G. X-ray diffraction approach to the mechanics of fatigue and fracture in metals. Mechanics Research Communications 1974, 1, 161-166, doi:10.1016/0093-6413(74)90008-1.

13. Leer, B.V.; Genc, A.; Passey, R. Ga+ and Xe+ FIB Milling and Measurement of FIB Damage in Aluminum. Microscopy and Microanalysis 2017, 23, 296-297, doi:10.1017/S1431927617002161.

14. Karbalaei Akbari, M.; Baharvandi, H.R.; Shirvanimoghaddam, K. Tensile and fracture behavior of nano/micro TiB2 particle reinforced casting A356 aluminum alloy composites. Materials \& Design (19802015) 2015, 66, 150-161, doi:10.1016/j.matdes.2014.10.048.

15. Lemaitre, J. How to use damage mechanics. Nuclear Engineering and Design 1984, 80, 233-245, doi:10.1016/0029-5493(84)90169-9.

16. Kelly, J.; Mohammadi, M. Uniaxial tensile behavior of sheet molded composite car hoods with different fibre contents under quasi-static strain rates. Mechanics Research Communications 2018, 87, 42-52, doi:10.1016/j.mechrescom.2017.12.007.

17. Szala, M.; Łukasik, D. Pitting Corrosion of the Resistance Welding Joints of Stainless Steel Ventilation Grille Operated in Swimming Pool Environment. International Journal of Corrosion 2018, 2018, doi:10.1155/2018/9408670.

18. Hutiu, G.; Duma, V.-F.; Demian, D.; Bradu, A.; Podoleanu, A.G. Assessment of Ductile, Brittle, and Fatigue Fractures of Metals Using Optical Coherence Tomography. Metals 2018, 8, 117, doi:10.3390/met8020117.

19. Kubit, A.; Trzepiecinski, T.; Faes, K.; Drabczyk, M.; Bochnowski, W.; Korzeniowski, M. Analysis of the effect of structural defects on the fatigue strength of RFSSW joints using C-scan scanning acoustic microscopy and SEM. Fatigue \& Fracture of Engineering Materials \& Structures 2019, 42, 1308-1321, doi:10.1111/ffe.12984. 
20. Lesiuk, G.; Szata, M.; Rozumek, D.; Marciniak, Z.; Correia, J.; De Jesus, A. Energy response of S355 and $41 \mathrm{Cr} 4$ steel during fatigue crack growth process. The Journal of Strain Analysis for Engineering Design 2018, 53, 663-675, doi:10.1177/0309324718798234.

21. Kasprzyczak, L.; Macha, E.; Marciniak, Z. Energy Parameter Control System of Strength Machine for Material Tests under Cyclic Bending and Torsion Available online: /SSP.198.489 (accessed on May 5, 2020).

22. Kowal, M.; Szala, M. Diagnosis of the microstructural and mechanical properties of over century-old steel railway bridge components. Engineering Failure Analysis 2020, 110, 104447, doi:10.1016/j.engfailanal.2020.104447.

23. Krawczyk, J.; Pacyna, J.; Bała, P. Fracture toughness of steels with nickel content in respect of carbide morphology. Materials Science and Technology 2015, 31, 795-802, doi:10.1179/1743284715Y.0000000023.

24. Derpeński, Ł. Ductile Fracture Behavior of Notched Aluminum Alloy Specimens under Complex NonProportional Load. Materials 2019, 12, 1598, doi:10.3390/ma12101598.

25. Żebrowski, R.; Walczak, M.; Korga, A.; Iwan, M.; Szala, M. Effect of Shot Peening on the Mechanical Properties and Cytotoxicity Behaviour of Titanium Implants Produced by 3D Printing Technology. Journal of Healthcare Engineering 2019, 2019, 8169538, doi:10.1155/2019/8169538.

26. Nový, F.; Bokůvka, O.; Trško, L.; Jambor, M. Safe choice of structural steels in a region of ultra-high number of load cycles. Production Engineering Archives 2019, 24, 25-28, doi:10.30657/pea.2019.24.06.

27. Walczak, M.; Pasierbiewicz, K.; Szala, M. Adhesion and Mechanical Properties of TiAlN and AlTiN Magnetron Sputtered Coatings Deposited on the DMSL Titanium Alloy Substrate. Acta Phys. Pol. A 2019, 136, 294-298, doi:10.12693/APhysPolA.136.294.

28. Maslarevic, A.; Bakic, G.M.; Djukic, M.B.; Rajicic, B.; Maksimovic, V.; Pavkov, V. Microstructure and Wear Behavior of MMC Coatings Deposited by Plasma Transferred Arc Welding and Thermal Flame Spraying Processes. Trans Indian Inst Met 2020, 73, 259-271, doi:10.1007/s12666-019-01831-9.

29. Szala, M.; Dudek, A.; Maruszczyk, A.; Walczak, M.; Chmiel, J.; Kowal, M. Effect of atmospheric plasma sprayed $\mathrm{TiO} 2-10 \% \mathrm{NiAl}$ cermet coating thickness on cavitation erosion, sliding and abrasive wear resistance. Acta Phys. Pol. A 2019, 136, 335-341, doi:10.12693/APhysPolA.136.335.

30. Slámečka, K.; Pokluda, J.; Ponížil, P.; Major, Š.; Šandera, P. On the topography of fracture surfaces in bending-torsion fatigue. Engineering Fracture Mechanics 2008, 75, 760-767, doi:10.1016/j.engfracmech.2007.01.018.

31. de Freitas, M.; Reis, L.; Meggiolaro, M.A.; de Castro, J.T.P. Stress scale factor and critical plane models under multiaxial proportional loading histories. Engineering Fracture Mechanics 2017, 174, 104-116, doi:10.1016/j.engfracmech.2016.12.016.

32. Karolczuk, A. Plastic strains and the macroscopic critical plane orientations under combined bending and torsion with constant and variable amplitudes. Engineering Fracture Mechanics 2006, 73, 1629-1652, doi:10.1016/j.engfracmech.2006.02.005.

33. Santus, C.; Taylor, D.; Benedetti, M. Experimental determination and sensitivity analysis of the fatigue critical distance obtained with rounded V-notched specimens. International Journal of Fatigue 2018, 113, 113-125, doi:10.1016/j.ijfatigue.2018.03.037.

34. Macek, W.; Wołczański, T. Analysis of fracture roughness parameters of S355J2 steel and EN AW-2017AT4 aluminium alloy. ITM Web Conf. 2017, 15, 06002, doi:10.1051/itmconf/20171506002. 
35. Macek, W.; Faszynka, S.; Deptuła, A. Fracture Surface Analysis of the EN AW-2017A-T4 Specimens with Rectangular Section. In Proceedings of the Mechatronics 2017 - Ideas for Industrial Applications; Świder, J., Kciuk, S., Trojnacki, M., Eds.; Springer International Publishing: Cham, 2019; pp. 290-297.

36. Singh, A.K.; Datta, S.; Chattopadhyay, A.; Riddick, J.C.; Hall, A.J. Fatigue crack initiation and propagation behavior in $\mathrm{Al}-7075$ alloy under in-phase bending-torsion loading. INT. J. FATIGUE 2019, 126, 346-356, doi:10.1016/j.ijfatigue.2019.05.024.

37. Valoroso, N.; Debruyne, G.; Laverne, J. A cohesive zone model with rate-sensitivity for fast crack propagation. Mechanics Research Communications $\quad \mathbf{2 0 1 4}, \quad 58, \quad 82-87$, doi:10.1016/j.mechrescom.2013.12.008.

38. Martins, R.F.; Ferreira, L.; Reis, L.; Chambel, P. Fatigue crack growth under cyclic torsional loading. Theoretical and Applied Fracture Mechanics 2016, 85, 56-66, doi:10.1016/j.tafmec.2016.08.016.

39. Macek, W. Post-failure fracture surface analysis of notched steel specimens after bending-torsion fatigue. Engineering Failure Analysis 2019, 105, 1154-1171, doi:10.1016/j.engfailanal.2019.07.056.

40. Macek, W. Fractal analysis of the bending-torsion fatigue fracture of aluminium alloy. Engineering Failure Analysis 2019, 99, 97-107, doi:10.1016/j.engfailanal.2019.02.007.

41. Marciniak, Z.; Rozumek, D.; Macha, E. Fatigue lives of 18G2A and 10HNAP steels under variable amplitude and random non-proportional bending with torsion loading. International Journal of Fatigue 2008, 30, 800-813, doi:10.1016/j.ijfatigue.2007.07.001.

42. Rozumek, D.; Faszynka, S. Fatigue crack growth in 2017A-T4 alloy subjected to proportional bending with torsion. Frattura ed Integrità Strutturale 2017, 11, 23-29, doi:10.3221/IGF-ESIS.42.03.

43. Kapłonek, W.; Nadolny, K.; Królczyk, G.M. The Use of Focus-Variation Microscopy for the Assessment of Active Surfaces of a New Generation of Coated Abrasive Tools. Measurement Science Review 2016, 16, 42-53, doi:10.1515/msr-2016-0007.

44. Newton, L.; Senin, N.; Gomez, C.; Danzl, R.; Helmli, F.; Blunt, L.; Leach, R. Areal topography measurement of metal additive surfaces using focus variation microscopy. Additive Manufacturing 2019, 25, 365-389, doi:10.1016/j.addma.2018.11.013.

45. Macek, W.; Rozumek, D.; Królczyk, G.M. Surface topography analysis based on fatigue fractures obtained with bending of the 2017A-T4 alloy. Measurement 2020, 152, 107347, doi:10.1016/j.measurement.2019.107347.

46. Neimitz, A.; Galkiewicz, J.; Lipiec, S.; Dzioba, I. Estimation of the Onset of Crack Growth in Ductile Materials. Materials 2018, 11, 2026, doi:10.3390/ma11102026.

47. Kim, J.; Kang, J.W.; Lee, D.-E.; Kim, D.Y. Methodology for Evaluation of Residual Stress Effect on Small Corner-Crack Initiation and Growth. Materials 2019, 12, 2904, doi:10.3390/ma12182904. 